ARTICLE

Received 10 Feb 2015 | Accepted 28 Apr 2015 | Published 4 Jun 2015

DOI: $10.1038 /$ ncomms 8345

OPEN

\title{
Phase and composition controllable synthesis of cobalt manganese spinel nanoparticles towards efficient oxygen electrocatalysis
}

\author{
Chun $\mathrm{Li}^{1}$, Xiaopeng Han ${ }^{1}$, Fangyi Cheng ${ }^{1,2}$, Yuxiang $\mathrm{Hu}^{1}$, Chengcheng $\mathrm{Chen}^{1} \&$ Jun $\mathrm{Chen}^{1,2}$
}

\begin{abstract}
Spinel-type oxides are technologically important in many fields, including electronics, magnetism, catalysis and electrochemical energy storage and conversion. Typically, these materials are prepared by conventional ceramic routes that are energy consuming and offer limited control over shape and size. Moreover, for mixed-metal oxide spinels (for example, $\mathrm{Co}_{x} \mathrm{Mn}_{3-x} \mathrm{O}_{4}$ ), the crystallographic phase sensitively correlates with the metal ratio, posing great challenges to synthesize active product with simultaneously tuned phase and composition. Here we report a general synthesis of ultrasmall cobalt manganese spinels with tailored structural symmetry and composition through facile solution-based oxidationprecipitation and insertion-crystallization process at modest condition. As an example application, the nanocrystalline spinels catalyse the oxygen reduction/evolution reactions, showing phase and composition co-dependent performance. Furthermore, the mild synthetic strategy allows the formation of homogeneous and strongly coupled spinel/carbon nanocomposites, which exhibit comparable activity but superior durability to $\mathrm{Pt} / \mathrm{C}$ and serve as efficient catalysts to build rechargeable $\mathrm{Zn}$-air and Li-air batteries.
\end{abstract}

\footnotetext{
${ }^{1}$ Key Laboratory of Advanced Energy Materials Chemistry (Ministry of Education) and State Key Laboratory of Elemento-Organic Chemistry, Nankai University, Tianjin 300071, China. ${ }^{2}$ Collaborative Innovation Center of Chemical Science and Engineering (Tianjin), Nankai University, Tianjin 300071, China. Correspondence and requests for materials should be addressed to J.C. (email: chenabc@nankai.edu.cn) or to F.C. (email: fycheng@nankai.edu.cn).
} 
S pinel-type compounds with the general formula of $\mathrm{AB}_{2} \mathrm{X}_{4}$ (A, $\mathrm{B}=$ metal, $\mathrm{X}=$ chalcogen) have attracted extensive interest because of their diverse properties and wide applications in electronics, catalysis, magnetism and electrochemical technologies such as batteries, fuel cells and electrolysers ${ }^{1-4}$. Spinels are traditionally synthesized through solid-state methods involving grinding and firing the mixtures of the corresponding metal oxides, nitrates or carbonates ${ }^{5,6}$, which require elevated temperature and prolonged time to overcome the reaction energy barriers ${ }^{7}$. The prepared spinels often show irregular shape, large particle size and low surface area, seriously affecting their physicochemical properties. Continuous efforts have been dedicated to developing alternative mild synthetic strategies such as hydro/solvothermal route $^{8}$, sol-gel $\operatorname{method}^{9}$ and carbonate co-precipitation ${ }^{10}$. However, it remains challenging to prepare homogenous and ultrasmall nanocrystalline spinels under mild conditions.

As a typical mixed transition metal spinel, cobalt manganese oxides $\left(\mathrm{Co}_{3-x} \mathrm{Mn}_{x} \mathrm{O}_{4}{ }_{\delta}\right)$ have versatile applications as lithium storage electrode, catalysts and magnetic materials ${ }^{8-12}$. The rational preparation of cobalt manganese spinels is made complex by different structural variations multiple oxidation states and elusive distribution of cations. Moreover, the crystallographic phases of $\mathrm{Co}_{3-x} \mathrm{Mn}_{x} \mathrm{O}_{4}$ are sensitively determined by the $\mathrm{Co} / \mathrm{Mn}$ ratio, namely, high $\mathrm{Mn}$ content $(1.9<x \leq 3)$ tends to form the tetragonal phase while low proportions of $\mathrm{Mn}(0 \leq x \leq 1.3)$ result in the cubic spinel at room temperature ${ }^{8,11}$. The Mn-enriched cubic spinel $(x=1.8)$ is observed at temperature around $998 \mathrm{~K}$ but is not stable at low temperature and immediately transforms into the tetragonal structure when quenching ${ }^{13}$. There seems to be a compositional limit to obtaining single cubic or tetragonal spinel phase at mild conditions. Theoretically, the lattice distortion caused by JahnTeller effect of $\mathrm{Mn}^{3}+\left(3 d^{4}\right)$ in octahedral interstices is responsible for the lowering of crystallographic symmetry from cubic to tetragonal phases ${ }^{14,15}$. If the cation $\mathrm{Mn}^{3+}$ concentration is low enough ( $\leq 60-65 \%)$, Jahn-Teller distortion would not be prominent and the spinels could exist in cubic form ${ }^{16}$. Therefore, it is feasible but remains a great challenge to rationally synthesize Co-Mn spinels with controlled phase over a wide composition range, which is highly desired in structuresensitive applications.

The catalytic oxygen reduction/evolution reactions (ORR/OER) determine performance of different electrochemical devices, including fuel cells, metal-air batteries and direct solar or electricity-driven water splitting ${ }^{17-19}$. Noble metal and alloys are the most active oxygen electrocatalysts ${ }^{20}$, but are expensive and scarce. Substantial efforts have been dedicated to improving the performance of Pt-based catalysts with minimal $\mathrm{Pt}$ loading ${ }^{21-24}$ or developing alternative catalysts based on nonnoble elements ${ }^{25-30}$. Multivalent metal spinels, $\mathrm{Co}_{3-x} \mathrm{Mn}_{x} \mathrm{O}_{4} \pm \delta$ in particular, are considered as attractive non-precious oxygen electrocatalysts ${ }^{8,11,29}$. However, the structure-properties relationship of spinel metal oxides remains elusive and their catalytic performances are limited relative to their Pt-based counterparts, because of low electrical conductivity and poor $\mathrm{O}_{2-}$ binding and -activating ability.

To develop efficient mixed $3 d$-metal-spinel catalysts with the above factors in mind, we describe herein a unique strategy for the rational synthesis of nanocrystalline $\mathrm{Co}_{3-x} \mathrm{Mn}_{x} \mathrm{O}_{4}(1 \leq x \leq 2)$ as well as $\mathrm{NiCo}_{2} \mathrm{O}_{4}, \mathrm{FeCo}_{2} \mathrm{O}_{4}, \mathrm{ZnCo}_{2} \mathrm{O}_{4}$ and $\mathrm{ZnMn}_{2} \mathrm{O}_{4}$. This solution-based synthesis involves oxidizing precipitation of $\mathrm{Mn} / \mathrm{Co}$ salts in air atmosphere and subsequent crystallization into spinels at mild temperature $\left(180^{\circ} \mathrm{C}\right)$. The approach yields $\sim 10 \mathrm{~nm}$ cobalt-manganese oxide (CoMnO) spinels with independently tunable crystallographic phase (cubic or tetragonal form) and $\mathrm{Co} / \mathrm{Mn}$ ratio, which is-to our knowledge-the first report of structural control over a wide compositional range of spinel $\left(\mathrm{Co}_{3}-{ }_{x} \mathrm{Mn}_{x} \mathrm{O}_{4}\right)$. In this case, the tetragonal form is extended in a composition range of $1 \leq x \leq 3$, while the cubic
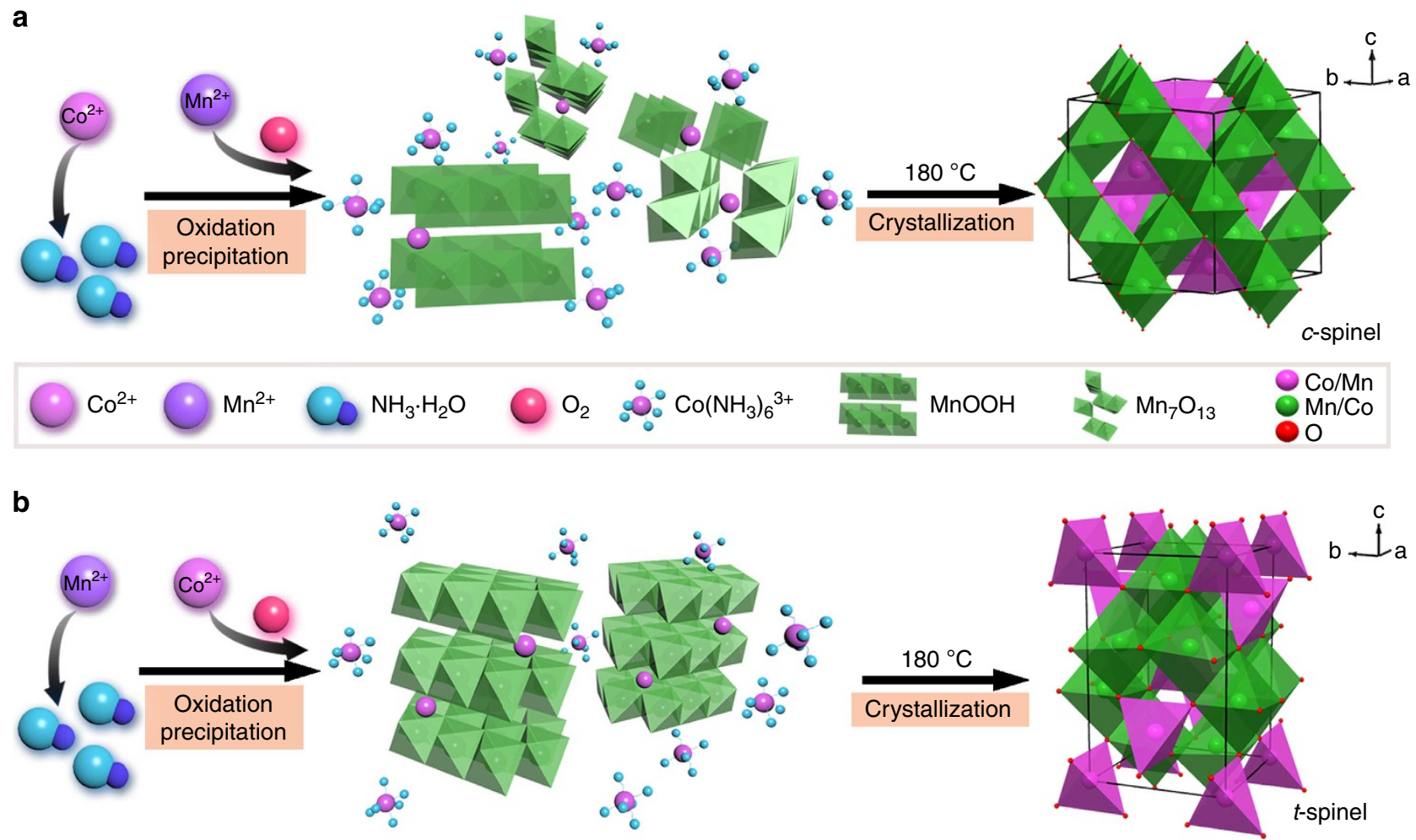

Figure 1 | Synthesis of CoMnO spinels. Schematic synthesis of cubic (a) and tetragonal (b) spinel phases, involving two steps of oxidation precipitation and crystallization. 
symmetry is attainable within $0 \leq x \leq 2$. The selective synthesis also allows the first systematical investigation of structureperformance correlation for $\mathrm{CoMnO}$ spinel electrocatalysts. We show that a cubic phase and a high Mn concentration in CoMnO spinels favour intrinsic ORR activity. We demonstrate that the nanocrystalline cubic spinel firmly supported on carbon manifests comparable ORR current and potential, but significantly better stability as compared with the commercial $\mathrm{Pt} / \mathrm{C}$ catalyst. Furthermore, the spinel-based electrocatalyst is catalytically efficient in air electrodes of rechargeable $\mathrm{Zn}$-air and $\mathrm{Li}$-air batteries.

\section{Results}

Synthesis and characterization of nanocrystalline spinels. As schematically shown in Fig. 1a,b, the rational synthesis proceeds through two steps, namely, a room-temperature oxidation precipitation of $\mathrm{Mn}^{2+} / \mathrm{Co}^{2+}$ with $\mathrm{NH}_{3} \bullet \mathrm{H}_{2} \mathrm{O}$ in air followed by a crystallization of spinel phase with cation redistribution on heating at $180^{\circ} \mathrm{C}$. We achieve phase selection by simply altering the adding order of reactants in the first step. To obtain a cubic spinel, aqueous $\mathrm{Mn}^{2+}$ is dripped into a solution containing $\mathrm{Co}^{2+}$ and $\mathrm{NH}_{3} \bullet \mathrm{H}_{2} \mathrm{O}$; the formation of tetragonal spinel follows reversely dripping $\mathrm{Co}^{2}+$ solution in a mixture of $\mathrm{Mn}^{2+}$ and $\mathrm{NH}_{3} \bullet \mathrm{H}_{2} \mathrm{O}$. We attain compositional control by adjusting the molar ratio of $\mathrm{Co} / \mathrm{Mn}$ precursors. Three representative compositions (Co:Mn=1:2, 1:1 and 2:1) in both cubic $(c-)$ and tetragonal $(t-)$ phases afford a batch of six spinel samples, which are designated as $c-\mathrm{CoMn}_{2}, c-\mathrm{CoMn}, c-\mathrm{Co}_{2} \mathrm{Mn}, t-\mathrm{CoMn}_{2}$, $t$-CoMn and $t-\mathrm{Co}_{2} \mathrm{Mn}$, respectively.

Figure 2a,b and Supplementary Fig. 1 display the X-ray diffraction patterns of the as-synthesized samples with the corresponding Rietveld refinement. The peak positions of Co-rich spinels shift to higher angles in both cubic and tetragonal phases (Fig. 2a). Reflection peaks of the cubic series (Fig. 2b; Supplementary Fig. 1a) are indexable to the space group Fd-3m (no.227) and consistent with the standard values of face-centered cubic phase (Joint Committee on Powder Diffraction Standards, JCPDS card no. 23-1237), while the pattern of the tetragonal series (Fig. 2b; Supplementary Fig. 1b) can be readily assigned to body-centered tetragonal spinel (space group I41/amd no. 141, JCPDS card no. 77-0471). The refined profiles match well with the experimental data and suggest the formation of spinel structure with cation or anion deficiency (Supplementary Tables 1-6; Supplementary Note 1). The slightly shifted diffraction peaks and decreased cell parameters of Co-rich oxides are ascribed to substitution of smaller $\mathrm{Co}^{3+}$ ions (radius
$\left.r_{\mathrm{Co}}^{3+}=0.545 \AA\right)$ for $\mathrm{Mn}^{3+}\left(r_{\mathrm{Mn}}^{3+}=0.645 \AA\right)$ on the octahedral sites. In comparison with spinels prepared from conventional ceramic routes, the $c$-series have a shrunken lattice, whereas the $t$-series possess larger cell parameters due to the presence of abundant ionic vacancies ${ }^{13,31}$

Typical scanning electron microscopy (SEM) images (Supplementary Fig. 2) show nanoparticulate morphology of the prepared spinel samples. As shown in transmission electron microscopy (TEM) images (Fig. 3a,b; Supplementary Fig. 3), the aggregated particles are composed of small nanocrystals having comparable mass-average particle sizes near $10 \mathrm{~nm}$ (Supplementary Fig. 4; Supplementary Note 2). The clear lattice fringes observed in high-resolution TEM and the corresponding fast Fourier transform (FFT) diffraction pattern (Fig. 3c,d) reveal the crystallinity and structural symmetry of the synthesized spinels. The interlayer spacing and well-defined points in FFT patterns coincide with the allowed Bragg diffraction of the corresponding cubic and tetragonal spinels, which agree with the $\mathrm{X}$-ray diffraction analysis. Moreover, energy-dispersive spectra (EDS, Supplementary Fig. 5) and elemental analysis from atomic absorption spectroscopy confirm the compositional ratio of $\mathrm{CoMn}_{2}$, CoMn and $\mathrm{Co}_{2} \mathrm{Mn}$ spinel compounds.

Synchrotron X-ray absorption spectroscopy analysis was performed to determine the oxidation states of mixed metals in the synthesized spinels ${ }^{32}$. Figure $4 \mathrm{a}$,b illustrates the Co and Mn K-edge X-ray absorption near-edge structure profiles. The reference cobalt and manganese oxides are also listed and used to establish the linear correlation between the K-edge excitation energy and the metal valence ${ }^{33}$. Accordingly, the mean Co valence was determined to be 2.25 for $c-\mathrm{CoMn}_{2}, t-\mathrm{CoMn}_{2}$ and $t$-CoMn and 2.38 for $c$-CoMn, $c-\mathrm{Co}_{2} \mathrm{Mn}$ and $t$ - $\mathrm{Co}_{2} \mathrm{Mn}$ (Fig. $4 \mathrm{c}$ ). A lower Co valence value tends to appear in oxides with lower Co content, suggesting an increase in the ratio of $\mathrm{Co}^{2+} / \mathrm{Co}^{3+}$ due to substitution of $\mathrm{Mn}$ cations ${ }^{8}$. As for Mn (Fig. 4d), the estimated average oxidation states of the cubic group (3.49, 3.45 and 3.28 for $c-\mathrm{CoMn}_{2}, \mathrm{CoMn}$ and $\left.\mathrm{Co}_{2} \mathrm{Mn}\right)$ are obviously higher than those of the tetragonal group $\left(2.84,2.76\right.$ and 2.67 for $t-\mathrm{CoMn}_{2}$, CoMn and $\mathrm{Co}_{2} \mathrm{Mn}$ ). Spectra of $\mathrm{Co}$ and $\mathrm{Mn}$ L-edge further confirm close Co electronic structure but dissimilar Mn valence (Supplementary Fig. 6). The different Mn oxidation states in the spinels are also verified by their thermal behaviours in air (Supplementary Fig. 7), where the mass loss of cubic phase within a moderate temperature range $\left(250-800^{\circ} \mathrm{C}\right)$ exceeds that of the corresponding tetragonal phase with the same composition. This difference implies more $\mathrm{Mn}^{4+}$ reduction to $\mathrm{Mn}^{3+}$ and higher $\mathrm{Mn}$ valence ${ }^{34}$ in cubic spinels than in tetragonal oxides.
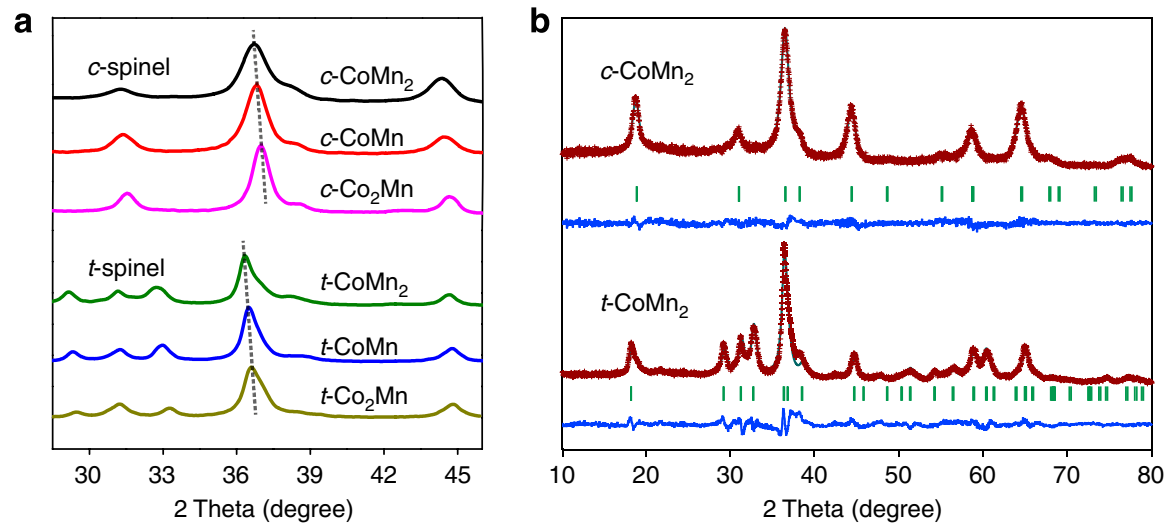

Figure 2 | Phases of CoMnO spinels. (a) X-ray diffraction patterns of synthesized six spinels and (b) Rietveld refined results of $c-, t$-CoMn $n_{2}$ spinels. Experimental data, calculated profiles, allowed Bragg diffraction positions and difference curve are marked with red dots, cyan line, vertical bars and blue line, respectively. 
The above results indicate controllable synthesis of cubic/ tetragonal spinel phase in an unprecedented wide composition of $\left(\mathrm{Co}_{3-x} \mathrm{Mn}_{x} \mathrm{O}_{4}, 1 \leq x \leq 2\right)$. Notably, to our knowledge, cubic $\mathrm{CoMn}_{2} \mathrm{O}_{4}$ and tetragonal $\mathrm{Co}_{2} \mathrm{MnO}_{4}$ have never been obtained at mild temperatures. To elucidate the formation mechanism of unusual phase, we have analysed the intermediate species during the synthesis (Supplementary Fig. 8). In preparation of cubic spinels, oxygen from air first oxidizes $\mathrm{Co}\left(\mathrm{NH}_{3}\right)_{6}^{2+}$ to $\mathrm{Co}\left(\mathrm{NH}_{3}\right)_{6}^{3+}$ in solution containing $\mathrm{Co}^{2+}$ and $\mathrm{NH}_{3} \bullet \mathrm{H}_{2} \mathrm{O}{ }^{35}$. After dripping $\mathrm{Mn}^{2+}, \mathrm{MnOOH}$ forms immediately and is gradually oxidized to cubic $\mathrm{Mn}_{7} \mathrm{O}_{13}$ in $\mathrm{Co}\left(\mathrm{NH}_{3}\right)_{6}^{3+}$, as evidenced by ex situ X-ray diffraction analysis of the precipitate and colour change of the
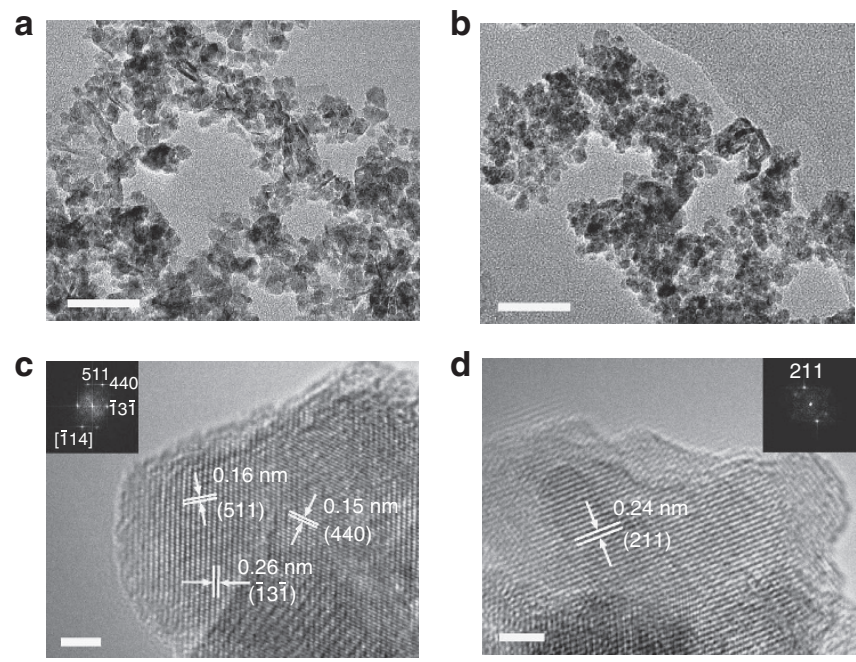

Figure 3 | Microstructures of the as-synthesized CoMnO spinels.

$(\mathbf{a}, \mathbf{b})$ TEM images showing the particulate shape and small size of $c-\mathrm{CoMn}_{2}$ (a) and $t-\mathrm{CoMn}_{2}$ (b). (c,d) High-resolution TEM images and FFT patterns (inset) showing the nanocrystalline characteristics of cubic (c) and tetragonal (d) phases. Scale bars, $50 \mathrm{~nm}(\mathbf{a}, \mathbf{b})$ and $2 \mathrm{~nm}(\mathbf{c}, \mathbf{d})$, respectively. solution (Supplementary Figs 8 and 9). The oxidative precipitation of $\mathrm{Mn}^{2+}$ to manganite is well known in alkaline solution exposed to $\mathrm{air}^{36}$, while the redox reaction $\left(7 \mathrm{MnOOH}+5 \mathrm{Co}\left(\mathrm{NH}_{3}\right)_{6}^{3+}+5 \mathrm{OH}^{-} \rightarrow \mathrm{Mn}_{7} \mathrm{O}_{13}+5 \mathrm{Co}\left(\mathrm{NH}_{3}\right)_{6}^{2+}\right.$ $+6 \mathrm{H}_{2} \mathrm{O}$, standard Gibbs free energy change $-139.53 \mathrm{~kJ} \mathrm{~mol}^{-1}$ ) is also thermodynamically favourable (Supplementary Note 3). The cubic crystal structure and high $\mathrm{Mn}$ valence of intermediate $\mathrm{Mn}_{7} \mathrm{O}_{13}$ (Supplementary Fig. 10) are responsible for the phase speciation of cubic spinel after crystallization on heating. In the synthesis of tetragonal spinels, the main precipitated intermediate is $\mathrm{MnOOH}$, which adopts tetragonal lattice with $\mathrm{Mn}$ (III) cations that tend to distort in lower crystallographic symmetry ${ }^{37}$.

Because the present synthesis of CoMnO spinels proceeds at relatively low temperature $\left(180^{\circ} \mathrm{C}\right)$, the product features small particle size and high specific surface area. The obtained $c-\mathrm{CoMn}_{2}, c-\mathrm{CoMn}, c-\mathrm{Co}_{2} \mathrm{Mn}, t-\mathrm{CoMn}, t-\mathrm{CoMn}$ and $t-\mathrm{Co}_{2} \mathrm{Mn}$ spinels have Brunauer-Emmett-Teller (BET) surface areas of $84,114,110,100,79$ and $73 \mathrm{~m}^{2} \mathrm{~g}^{-1}$ (Supplementary Fig. 11), respectively, which are obviously higher than those of CoMnO spinel powders prepared using the conventional high-temperature ceramic method ${ }^{29}$ (Supplementary Fig. 12). The mild synthesis results in abundant ionic deficiency and low crystallinity, which can be enhanced by annealing (Supplementary Fig. 13). Thermal treatment also induces lower Mn valence as well as larger cell parameter and increased average metal-oxygen bond length in octahedron (Supplementary Table 7). Of particulate note, the unusual $c-\mathrm{CoMn}_{2}$ and $t$ - $\mathrm{Co}_{2} \mathrm{Mn}$ spinels undergo cubic $\leftrightarrows$ tetragonal transition at high temperature (Supplementary Fig. 14), which is consistent with previous report ${ }^{13}$ and suggests that $c-\mathrm{CoMn}_{2}$ and $t-\mathrm{Co}_{2} \mathrm{Mn}$ are metastable. These results demonstrate the successful simultaneous control of crystallographic symmetry and composition of CoMnO spinels.

Electrocatalytic ORR properties of CoMnO spinels. The controllable preparation of $\mathrm{CoMnO}$ spinels series permits a systematical investigation of their structure-performance
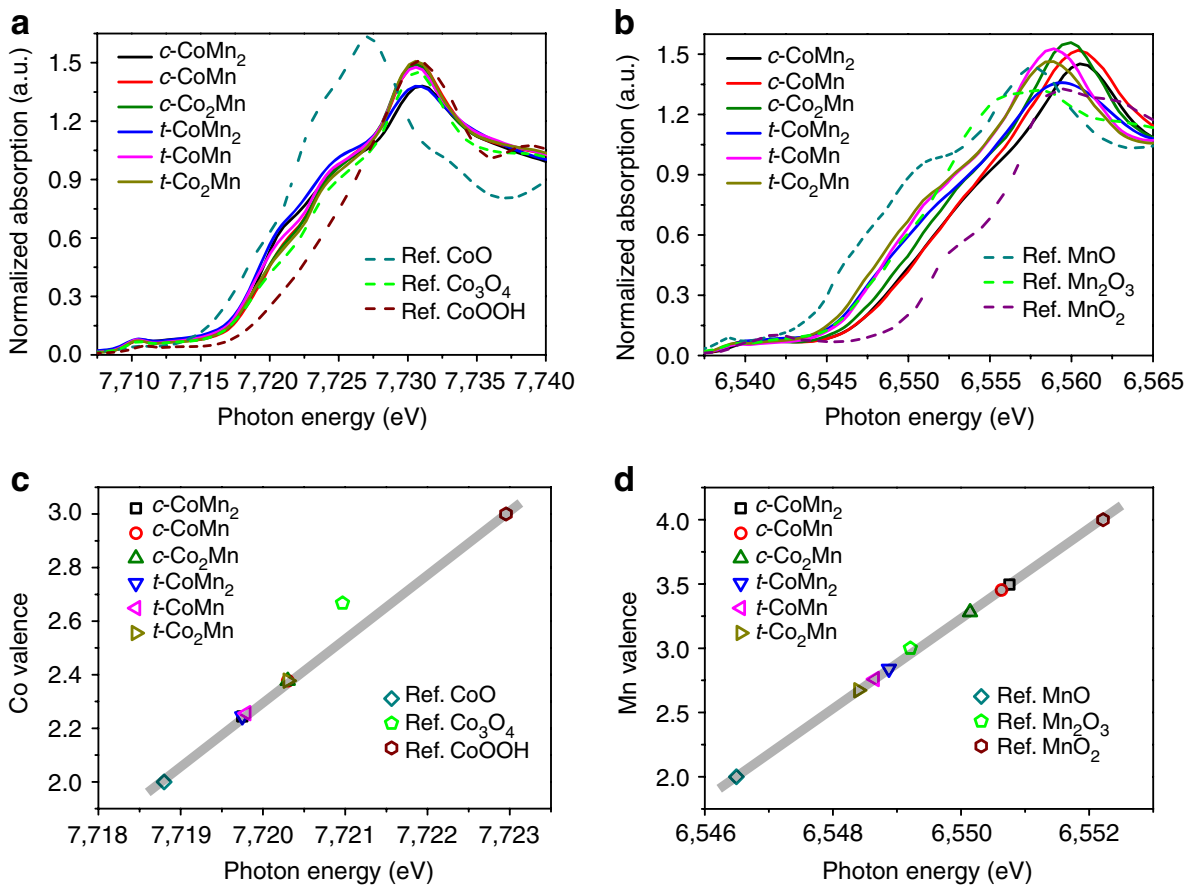

Figure 4 | X-ray absorption near-edge structure (XANES) analysis of metal valence. (a,b) K-edge XANES patterns of Co (a) and Mn (b) in the synthesized spinels and the reference oxides. (c,d), Fitted linear relationship between the photon energy and oxidation state of Co (c) or Mn (d). 
a

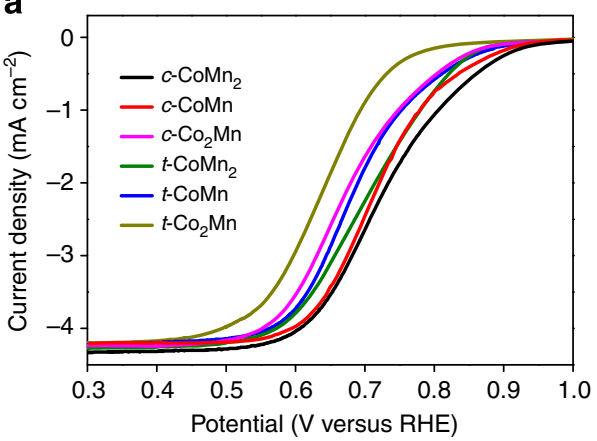

C

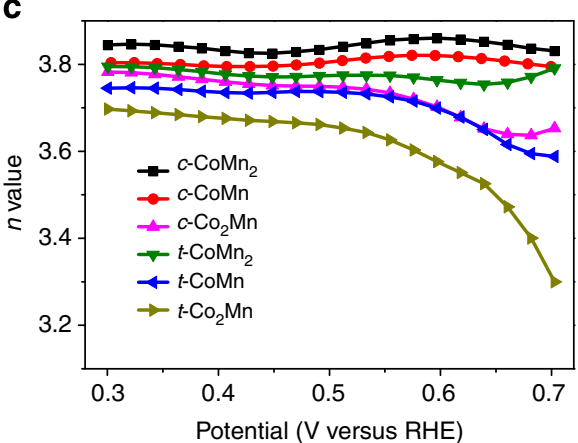

b

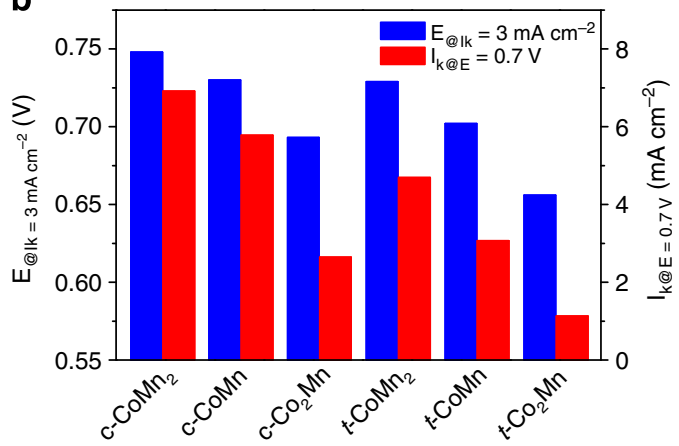

d

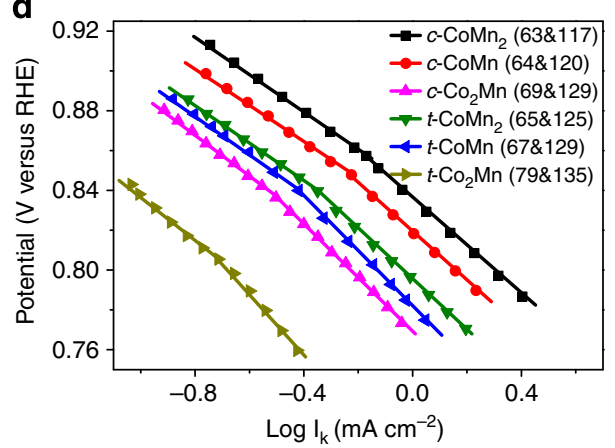

Figure 5 | ORR electrocatalytic properties of CoMnO spinels. (a), Voltammograms in $\mathrm{O}_{2}$-saturated $0.1 \mathrm{M} \mathrm{KOH}$ electrolyte by subtracting the voltammograms in Ar. The electrode rotation rate is 900 r.p.m. (b), Kinetic current densities at $0.7 \mathrm{~V}$ and required potentials for $I_{\mathrm{k}}=3 \mathrm{mAcm} \mathrm{cm}^{-2}$. (c), Electron transfer number $(n)$ at different potentials. (d), Tafel plots constructed from the voltammetry data. The slope unit is $\mathrm{mV}$ dec ${ }^{-1}$.

relationship towards the oxygen electrocatalysis. Figure 5 shows the ORR catalytic properties of the nanocrystalline spinels supported on rotational glass-carbon electrodes. The polarization profiles (Fig. 5a) display typical ORR current-potential response $^{21-23}$, by subtracting the voltammograms in Ar. There emerges a mixed kinetic diffusion-controlled region at $0.9-0.5 \mathrm{~V}$ versus reversible hydrogen electrode and a subsequent oxygen-transport-limited current $\left(I_{\mathrm{d}}\right)$, which increases with electrode-rotating rates (Supplementary Fig. 15). The catalytic activities of the spinels can be accessed directly by the onset and half-wave potentials. Evidently, the cubic spinel outperforms the corresponding tetragonal phase having the same composition, while for either cubic or tetragonal structures, the activities decrease with Co:Mn ratio, following an order of $\mathrm{CoMn}_{2}>\mathrm{CoMn}>\mathrm{Co}_{2} \mathrm{Mn}$. The different performance can be also viewed from the required potentials to reach a given kinetic current $\left(I_{\mathrm{k}}\right)$ or the $I_{\mathrm{k}}$ values at a given potential (Fig. 5b).

Further evaluation of the ORR catalytic behaviours is performed by determining the transferred electron number $(n)$, and yield of peroxide species from the disk and ring currents recorded on rotational disk-ring electrodes (Fig. 5c; Supplementary Fig. 16; Supplementary Note 4). Below $0.55 \mathrm{~V}, n$ is above 3.60 , which coincides with the results based on KouteckyLevich $^{8,28}$ plots (Supplementary Fig. 15; Supplementary Note 5) and suggests an apparent quasi- $4 \mathrm{e}^{-}$ORR pathway. A comparison of determined $n$ values for six nanocrystalline spinels demonstreates the superiority of cubic phase and high Mn content. In addition, two Tafel slopes observed at high and low overpotentials imply similar reaction mechanism and ratedetermining step for all spinels (Fig. 5d), in accordance with previously reported manganese oxide electrocatalysts ${ }^{38}$. Again, the activities of different spinels are distinguishable by the overpotential and kinetic current density. It is deserved to note that the ORR activities of synthesized nanocrystalline CoMnO spinel surpass that of the counterparts prepared using hightemperature ceramic method (Supplementary Fig. 17); this superiority could be mainly ascribed to the smaller crystalline size and higher specific surface areas. Besides, the obtained spinel renders respectable catalytic capability in neutral ( $\mathrm{KCl}$ solution) or nonaqueous (ether-based electrolyte) media (Supplementary Fig. 18).

Supplementary Table 8 summarizes the ORR electrocatalytic characteristics (for example, onset and half-wave potentials, transferred electron number and kinetic currents normalized by mass or specific surface areas) of the spinel series, indicating structure and composition co-dependent behaviour. Specifically, cubic phase and higher $\mathrm{Mn} / \mathrm{Co}$ ratio are more favourable in intrinsic activity. In alkaline media, the ORR electrocatalysis on transition metal oxides is proposed to involve multistep steps of $\mathrm{O}_{2}$ adsorption, formation of an $\mathrm{HO}_{2}^{-}$intermediate and further reduction or decomposition of peroxide to $\mathrm{OH}^{-}$ions ${ }^{28}$. These processes are mediated by electron transfer and redox reactions of metal-containing species, and strongly related to the number of available active sites and the surface oxygen adsorption ability that can be tuned by electronic structure ${ }^{38,39}$. Following this mechanistic consideration, the structure-property correlation of $\mathrm{CoMnO}$ spinels can be understood as follows. First, cubic spinel surfaces provide more catalytic sites number and bind $\mathrm{O}_{2}$ more strongly than the tetragonal phase, as previously demonstrated ${ }^{29}$. The slightly stronger interaction between cubic spinel and adsorbed oxygen is verified here by X-ray photoelectron spectroscopy (XPS, Supplementary Fig. 19). Second, the cubic phases feature a higher average oxidation state of $\mathrm{Mn}(>3)$, which exists in a mixed form of $\mathrm{Mn}^{3+}$ and $\mathrm{Mn}^{4+}$ cations. The presence of multivalent $3 d$ metals would benefit electron conduction (by hopping) and charge transfer (through redox reactions), thus favouring the electrocatalysis ${ }^{40}$. The electrical conductivity of neat $c-\mathrm{CoMn}_{2}$ is $1.01 \mathrm{~S} \mathrm{~m}^{-1}$, a value at least three 
orders of magnitude higher than that of the binary $\mathrm{Co}_{3} \mathrm{O}_{4}$ and $\mathrm{Mn}_{3} \mathrm{O}_{4}$ spinels (Supplementary Fig. 20). Third, the compositiondependent kinetics is interpretable by the factor that $\mathrm{Co}$ (II) is less active than $\mathrm{Mn}$ species ${ }^{8}$. Furthermore, based on O K-edge X-ray absorption spectroscopy analysis (Supplementary Fig. 6), we find a moderate affinity between surface metal cation and absorbed oxygen-containing species in both $c-\mathrm{CoMn}_{2}$ and $t-\mathrm{CoMn}_{2}$ spinels, which would facilitate the rate-limiting steps of hydroxide/ peroxide displacement and regeneration during the $\mathrm{ORR}^{28}$.

Application of carbon-supported CoMnO spinels. Our one-pot synthesis offers a simple, general and in situ approach to fabricate mixed-metal oxide supported on conducting substrate composite materials with high electronic conductivity and uniformly distributed active sites. Here we show an example of the hybrid (Supplementary Fig. 21) comprising the most active $c$-CoMn spinel and Carbot Vulcan XC-72 carbon (a widely used electrocatalyst support ${ }^{29}$ ), which is abbreviated as $c$-CoMn $2 /$ C. TEM image (Fig. 6a) of the composite reveals that $c$-CoMn nanoparticles are uniformly dispersed on the carbon support with firm attachment. The composition of the hybrid can be easily adjusted and a $\sim 30 \mathrm{wt} \%$ spinel is found to attain the best ORR activity (Supplementary Fig. 22).

The as-synthesized $c$-CoMn $2 / \mathrm{C}$ composite delivers significantly enhanced ORR and OER performance as compared with the physical mixture of two components (Fig. 6b). More surprisingly, the ORR activity of the hybrid rivals that of the benchmark $\mathrm{Pt} / \mathrm{C}$ catalyst (30 wt\% Pt nanoparticles supported on Vulcan XC-72 carbon, Supplementary Fig. 23); for the OER the former far exceeds the latter. The similar fitted K-L plots (Fig. 6c) and determined electron transfer number and percentage of peroxide (Fig. 6d) also demonstrate the comparable catalytic performance between the hybrid and $\mathrm{Pt} / \mathrm{C}$. In addition, the calculated ORR turnover frequency (Supplementary Note 6) at $0.80 \mathrm{~V}$ is $0.69,1.07$ and $0.07 \mathrm{~s}^{-1}$ for $\mathrm{Pt} / \mathrm{C}, c-\mathrm{CoMn}_{2} / \mathrm{C}$, and the physical mixture, respectively. The key performance parameters such as onset potential, half-wave potential, kinetic current density and electron transfer number of $c-\mathrm{CoMn}_{2} / \mathrm{C}$ are among the most active non-noble metal electrocatalysts reported so far ${ }^{8,27-29,41}$ (Supplementary Table 9). Electrochemical impedance spectroscopy (Supplementary Fig. 24) shows much lower charge transfer resistance on $c$ - $\mathrm{CoMn}_{2} / \mathrm{C}$ than on $c-\mathrm{CoMn}_{2}+\mathrm{C}$ mixture, which is likely an attribution to the faster ORR kinetics of the in situ a

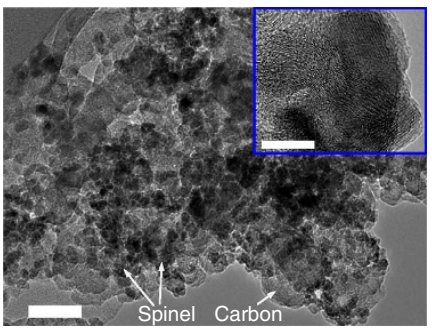

C

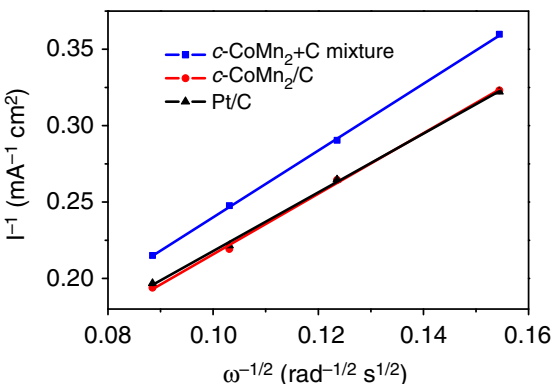

e

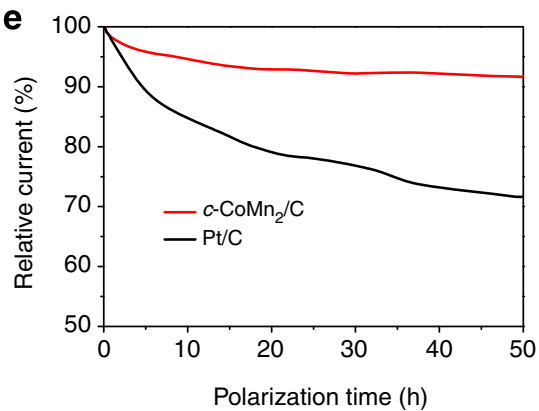

b
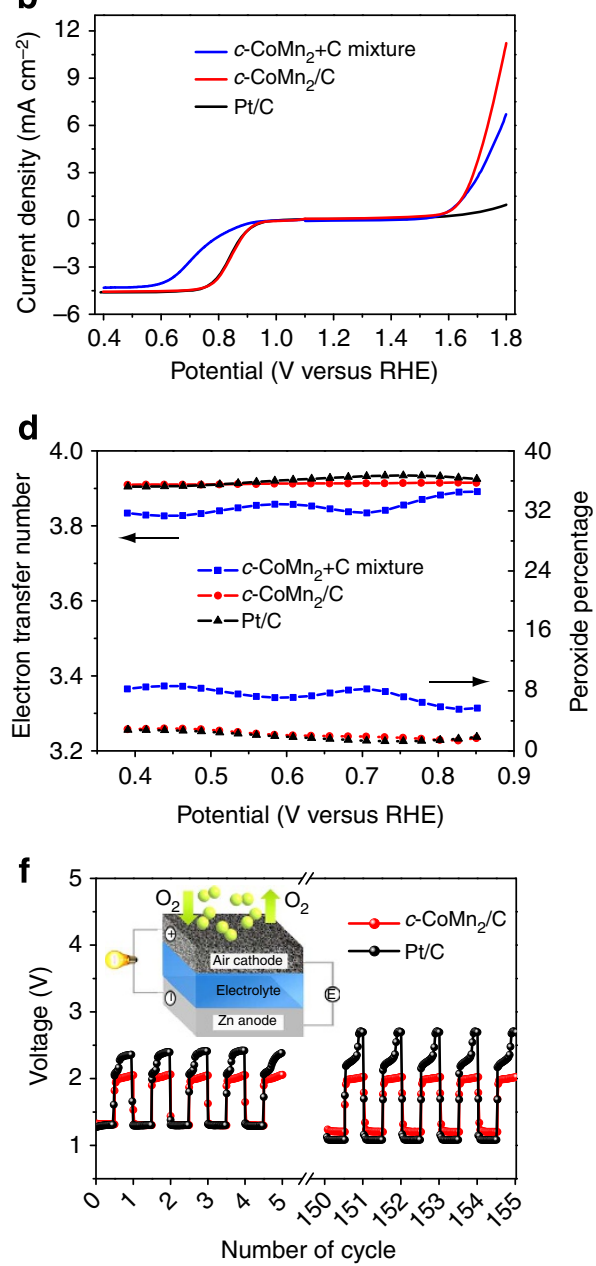

Figure 6 | Carbon-supported CoMnO spinel for ORR/OER and metal-air batteries. (a), TEM image of prepared c-CoMn $/$ C hybrid (scale bar, 50 nm). Inset shows firm anchoring of a single spinel nanoparticle on carbon (scale bar, $10 \mathrm{~nm}$ ). (b), Comparison of ORR and OER activities of c-CoMn $\mathrm{O}_{2}+\mathrm{C}$ mixture, $\mathrm{c}-\mathrm{CoMn}_{2} / \mathrm{C}$ hybrid and $\mathrm{Pt} / \mathrm{C}$ catalyst in $0.1 \mathrm{M} \mathrm{KOH}$ solution. The rotation rate is 900 r.p.m. during the ORR. (c), K-L plots at $0.65 \mathrm{~V}$. (d), Electron transfer number and peroxide percentage generated at various potentials. (e), Chronoamperometric responses of $\mathrm{c}-\mathrm{CoMn} / \mathrm{C}$ and $\mathrm{Pt} / \mathrm{C}$ at $0.8 \mathrm{~V}$ in $\mathrm{O}_{2}$-saturated $0.1 \mathrm{M} \mathrm{KOH}$. (f), Performance of rechargeable $\mathrm{Zn}$-air cells based on $\mathrm{c}-\mathrm{CoMn}_{2} / \mathrm{C}$ and Pt/C catalysts at a cycling rate of $10 \mathrm{~mA} \mathrm{~cm}^{-2}$ and a duration of $400 \mathrm{~s}$ per cycle. Inset schematically depicts the structure of assembled rechargeable $\mathrm{Zn}$-air cells. 
generated hybrid. Apart from high activity, $c$ - $\mathrm{CoMn}_{2} / \mathrm{C}$ exhibits remarkable catalytic stability. In a continuous chronoamperometric period of $50 \mathrm{~h}$, the retention of ORR current on $c-\mathrm{CoMn}_{2} / \mathrm{C}$ sustains $>91.5 \%$, significantly higher than that of $\mathrm{Pt} / \mathrm{C}$ (71.6\%) (Fig. 6e). The morphology of the hybrid remains almost unchanged even after repeated 12,000 cyclic voltammograms, whereas Pt nanoparticles agglomerate severely in $\mathrm{Pt} / \mathrm{C}$ (Supplementary Fig. 25), indicating considerable structural robustness of $c$ - $\mathrm{CoMn}_{2} / \mathrm{C}$. The superior performance of the hybrid possibly arises from several factors: (1) the intrinsic high activity of $c-\mathrm{CoMn}_{2}$ spinel (Supplementary Table 8); (2) the high dispersion, small size of nanocrystalline spinel; and (3) the strong coupling effect between the spinel oxide and the carbon substrate functionalized with nitrogen groups, as evidenced by XPS results (Supplementary Fig. 26). The firm contact of spinel and carbon in the in situ fabricated hybrid also favours enhanced electrical conductivity in comparison with the physical mixture (Supplementary Fig. 20).

The superb electrocatalytic performance of synthesized $c-\mathrm{CoMn}_{2} / \mathrm{C}$ has motivated us to investigate its applicability in metal-air battery devices. The assembled primary $\mathrm{Zn}$-air cells exhibit stable galvanostatic discharge curves, giving a high energy density of $\sim 650 \mathrm{Wh} \mathrm{kg}^{-1}$ at $10 \mathrm{~mA} \mathrm{~cm}^{-2}$ normalized to consumed $\mathrm{Zn}$ anode (Supplementary Fig. 27). More interestingly, the constructed cells show exceptional rechargeability at a shallow discharge/charge state (Fig. 6f). Due to the superior bifunctinal ORR/OER capability and durability, the $c$ - $\mathrm{CoMn}_{2} / \mathrm{C}$ composite electrocatalyst enables lower discharge/charge overpotential and more stable voltage plateau on cycling, as compared to that of $\mathrm{Pt} / \mathrm{C}$. For $c$-CoMn $2 / \mathrm{C}$-based cell, the average voltage of discharge platform decreases by $8.5 \%$ after 155 cycles, half that of $\mathrm{Pt} / \mathrm{C}$ $(17.6 \%)$. The variation of charging potential for $c-\mathrm{CoMn}_{2} / \mathrm{C}$ electrode is negligible, whereas the $\mathrm{Pt} / \mathrm{C}$-based cell suffers a increase of $14.4 \%$. Furthermore, the spinel-based cathode applied in lithium-air cells delivers high capacity and encouraging cyclability up to dozens of cycles (Supplementary Fig. 28). These results suggest that the $c-\mathrm{CoMn}_{2} / \mathrm{C}$ nanocomposite is an effective, yet durable catalyst for catalysing dual ORR and OER in rechargeable metal-air batteries.

\section{Discussion}

We have synthesized nanocrystalline cobalt-manganese spinel oxides with simultaneously controllable phase and composition using a facile oxidation-precipitation and crystallization route. The synthesis allows tuning the cubic and tetragonal crystallographic symmetry of spinel over an unprecedented wide compositional range $\left(\mathrm{Co}_{3}{ }_{x} \mathrm{Mn}_{x} \mathrm{O}_{4}, 1 \leq x \leq 2\right)$ at mild temperature and room atmosphere. The obtained spinel family is featured by variable metal valence, small particle size, high specific surface areas and abundant ionic defects. It deserves to note that this solution-based synthetic strategy can be extended to the preparation of other technologically important nanocrystalline spinel oxides such as $\mathrm{NiCo}_{2} \mathrm{O}_{4}, \mathrm{FeCo}_{2} \mathrm{O}_{4}, \mathrm{ZnCo}_{2} \mathrm{O}_{4}$ and $\mathrm{ZnMn}_{2} \mathrm{O}_{4}$ at temperatures below $200^{\circ} \mathrm{C}$ (Supplementary Fig. 29), although the structural symmetry control of these spinels has not been attained possibly owing to the limit of valence tunability and the strong lattice-site preference of $\mathrm{Ni}$, $\mathrm{Fe}$ and $\mathrm{Zn}$ relative to $\mathrm{Co}$ and $\mathrm{Mn}$.

When employed as electrocatalysts for the ORR in alkaline media, the as-synthesized spinel nanocrystallines outperform the high-temperature powders. The intrinsic electrocatalytic activity of $\mathrm{CoMnO}$ family correlates with the crystal phase, $\mathrm{Co} / \mathrm{Mn}$ composition and surface valence value that affect the extent of $\mathrm{O}_{2}$ activation and number of available active sites. Furthermore, the solution-based synthesis at mild temperatures enables in situ, firmly dispersing ultrafine spinel nanoparticles on conducting substrates such as carbon. The optimized $c-\mathrm{CoMn}_{2} / \mathrm{C}$ hybrid manifests similar ORR performance and superior catalytic durability to that of the counterpart $\mathrm{Pt} / \mathrm{C}$ catalyst. The $c-\mathrm{CoMn}_{2} / \mathrm{C}$ nanocomposite is also active for the OER, rendering bifunctional electrocatalytic capability. These results would shed light on rational design and preparation of spinel oxides and broaden their applications, for example, as efficient catalysts for oxygen-relevant energy storage technologies including rechargeable metal-air batteries and regenerative fuel cells.

\section{Methods}

Synthesis. In a typical synthesis of cubic nanocrystalline $\mathrm{CoMn}_{2}$ spinel, $4 \mathrm{ml}$ aqueous ammonia (25 wt\%) was first dropped into $5 \mathrm{ml} 0.2 \mathrm{moll}^{-1} \mathrm{Co}\left(\mathrm{NO}_{3}\right)_{2}$ solution under constant stirring at room temperature. Then, $10 \mathrm{ml}$ of $0.2 \mathrm{moll}^{-1}$ $\mathrm{Mn}\left(\mathrm{NO}_{3}\right)_{2}$ solution was added to the mixture, which was stirred for $120 \mathrm{~min}$. Afterwards, the mixture was evaporated and nitrates were fully decomposed by heating at $180^{\circ} \mathrm{C}$ for $40 \mathrm{~min}$, yielding cubic $\mathrm{CoMn}_{2}$. Similarly, cubic CoMn and $\mathrm{Co}_{2} \mathrm{Mn}$ samples were obtained by adopting the corresponding stoichiometric amount of cobalt and manganese sources, respectively. In preparation of tetragonal $\mathrm{CoMn}_{2}, 4 \mathrm{ml}$ aqueous ammonia (25 wt\%) was dropped into $10 \mathrm{ml} 0.2 \mathrm{moll}^{-1}$ $\mathrm{Mn}\left(\mathrm{NO}_{3}\right)_{2}$ solution, subsequently followed by addition of $5 \mathrm{ml} 0.2 \mathrm{moll}^{-1}$ $\mathrm{Co}\left(\mathrm{NO}_{3}\right)_{2}$ aqueous solution, water evaporation and heating. Likewise, tetragonal CoMn and $\mathrm{Co}_{2} \mathrm{Mn}$ spinels were synthesized by adjusting the Co:Mn molar ratio. The spinel/carbon hybrid was obtained by simply dispersing desired amount of carbon powders in the aqueous $\mathrm{Co} / \mathrm{Mn}$ salt solution.

Characterization. Powder X-ray diffraction patterns were collected on a Rigaku MiniFlex600 X-ray diffractometer with $\mathrm{Cu} K \alpha$ radiation. The X-ray diffraction data was refined by the RIETAN-2,000 Rietveld refinement program ${ }^{42}$. SEM images were taken with a JEOL JSM-7500F microscope (operating voltage, $5 \mathrm{kV}$ ) equipped with an EDS analyzer. TEM and high-resolution TEM imaging was obtained on Philips Tecnai G2 F20 (acceleration voltage, $200 \mathrm{kV}$ ). Chemical composition was determined by EDS and atomic absorption spectrometry (AAS, Hitachi 180-90 spectrophotometer). Surface areas were calculated from the $\mathrm{N}_{2}$ adsorption/ desorption isotherms at $77 \mathrm{~K}$ on BELsorp-Mini. Thermogravimetric analysis was carried out on a Netzsch STA 449 F3 Jupiter analyzer. XPS was performed by a Perkin Elmer PHI 1,600 ESCA system. The X-ray absorption near-edge structure spectra were collected on BL14W1 beamline of Shanghai Synchrotron Radiation Facility (SSRF) and analysed with software of Ifeffit Athena.

Electrochemical test. Electrochemical tests were performed using a standard three-electrode electrochemical cell comprising a saturated calomel reference electrode, a platinum foil counter electrode and a glass-carbon working electrode coated with catalyst. The fabrication of working electrode followed similar procedures described previously ${ }^{40}$. Typically, a mixture of $1.5 \mathrm{mg}$ spinels and $3.5 \mathrm{mg}$ carbon powder (Vulcan XC-72) or $5 \mathrm{mg} c-\mathrm{CoMn}_{2} / \mathrm{C}$ hybrid was dispersed in solvent containing $0.5 \mathrm{ml}$ water, $0.5 \mathrm{ml}$ isopropyl alcohol and $17.5 \mu \mathrm{l}$ neutralized Nafion solution (5 wt\%, Sigma-Aldrich). After thorough sonication, $4.6 \mu \mathrm{l}$ of the formed catalyst ink was pipetted on the glassy carbon electrode, which was air-dried to afford a mass loading of $\sim 0.054 \mathrm{mg}_{\text {oxide }} \mathrm{cm}^{-2}$. The electrolyte was $0.1 \mathrm{M}$ aqueous $\mathrm{KOH}, 0.1 \mathrm{M} \mathrm{KCl}$ and $1.0 \mathrm{M}$ lithium bis(trifluoromethane) sulfonamide (LiTFSI) in tetraethylene glycol dimethyl ether (TEGDME) in the case of alkaline, neutral and aprotic media, respectively. The electrolyte was purged with $\mathrm{O}_{2}$ for 30 min before each measurement and subjected to $\mathrm{O}_{2}$ flow during the tests. Electrochemical data were recorded at room temperature on a PARSTAT $263 \mathrm{~A}$ workstation accompanied with a model 636 system (AMETEK). The voltammetry was collected at a potential scan rate of $5 \mathrm{mV} \mathrm{s}^{-1}$. The polarization voltammograms in $\mathrm{O}_{2}$-saturated electrolyte have been corrected by subtracting the background current recorded in Ar-saturated electrolyte. All potentials were calibrated with reference to standard reversible hydrogen electrode. Electrochemical impedance spectra were conducted on PARSTAT 4,000 (AMETEK) with a frequency range of $100 \mathrm{kHz}-100 \mathrm{mHz}$. The $\mathrm{Li}$-air and $\mathrm{Zn}$-air cells were assembled with a $\mathrm{Li}$ or $\mathrm{Zn}$ anode, a spinel catalyst-based cathode and a LiTFSI/TEGDME or KOH electrolyte. Battery performance testing was conducted on a LAND-CT2001A system at room temperature.

\section{References}

1. Yamasaki, Y. et al. Magnetic reversal of the ferroelectric polarization in a multiferroic spinel oxide. Phys. Rev. Lett. 96, 207204 (2006).

2. Hemberger, J. et al. Relaxor ferroelectricity and colossal magnetocapacitive coupling in ferromagnetic $\mathrm{CdCr}_{2} \mathrm{~S}_{4}$. Nature 434, 364-367 (2005).

3. Xie, X. W. et al. Low-temperature oxidation of $\mathrm{CO}$ catalysed by $\mathrm{Co}_{3} \mathrm{O}_{4}$ nanorods. Nature 458, 746-749 (2009).

4. Thackeray, M. M. Manganese oxides for lithium batteries. Prog. Solid State Chem. 25, 1-71 (1997) 
5. Armijo, J. S. The kinetics and mechanism of solid-state spinel formation-A review and critique. Oxid. Met. 1, 171-198 (1969).

6. Lu, J. et al. Effectively suppressing dissolution of manganese from spinel lithium manganate via a nanoscale surface-doping approach. Nat. Commun. 5, 5693 (2014).

7. Stein, A., Keller, S. W. \& Mallouk, T. E. Turning down the heat: design and mechanism in solid-state synthesis. Science 259, 1558-1564 (1993).

8. Liang, Y. Y. et al. Covalent hybrid of spinel manganese-cobalt oxide and graphene as advanced oxygen reduction electrocatalysts. J. Am. Chem. Soc. 134, 3517-3523 (2012).

9. Lavela, P., Tirado, J. L. \& Vidal-Abarca, C. Sol-gel preparation of cobalt manganese mixed oxides for their use as electrode materials in lithium cells. Electrochim. Acta 52, 7986-7995 (2007).

10. Zhou, L., Zhao, D. \& Lou, X. W. Double-shelled $\mathrm{CoMn}_{2} \mathrm{O}_{4}$ hollow microcubes as high-capacity anodes for lithium-ion batteries. Adv. Mater. 24, 745-748 (2012).

11. Rios, E., Gautier, J. L., Poillerat, G. \& Chartier, P. Mixed valency spinel oxides of transition metals and electrocatalysis: case of the $\mathrm{Mn}_{\mathrm{x}} \mathrm{Co}_{3-\mathrm{x}} \mathrm{O}_{4}$ system. Electrochim. Acta 44, 1491-1497 (1998).

12. Habjanič, J. et al. A 3D oxalate-based network as a precursor for the $\mathrm{CoMn}_{2} \mathrm{O}_{4}$ spinel: synthesis and structural and magnetic studies. Inorg. Chem. 53, 9633-9643 (2014).

13. Vila, E., Rojas, R. M., Martín de Vidales, J. L. \& García-Martínez, O. Structural and thermal properties of the tetragonal cobalt manganese spinels $\mathrm{Mn}_{\mathrm{x}} \mathrm{Co}_{3-\mathrm{x}} \mathrm{O}_{4}$ $(1.4<\mathrm{x}<2.0)$. Chem. Mater. 8, 1078-1083 (1996).

14. Goodenough, J., Wold, A., Arnott, R. \& Menyuk, N. Relationship between crystal symmetry and magnetic properties of ionic compounds containing $\mathrm{Mn}^{3+}$. Phys. Rev. 124, 373-384 (1961).

15. Goodenough, J. \& Loeb, A. Theory of ionic ordering, crystal distortion, and magnetic exchange due to covalent forces in spinels. Phys. Rev. 98, 391-408 (1955).

16. Buhl, R. Manganites spinelles purs d'elements de transition preparations et structures cristallographiques. J. Phys. Chem. Solids 30, 805-812 (1969).

17. Bruce, P. G., Freunberger, S. A., Hardwick, L. J. \& Tarascon, J. M. Li- $\mathrm{O}_{2}$ and Li-S batteries with high energy storage. Nat. Mater. 11, 19-29 (2012).

18. Malavasi, L., Fisher, C. A. J. \& Islam, M. S. Oxide-ion and proton conducting electrolyte materials for clean energy applications: structural and mechanistic features. Chem. Soc. Rev. 39, 4370-4387 (2010).

19. Kinoshita, K. Electrochemical Oxygen Technology (Wiley, 1992).

20. Debe, M. K. Electrocatalyst approaches and challenges for automotive fuel cells. Nature 486, 43-51 (2012).

21. Yamamoto, K. et al. Size-specific catalytic activity of platinum clusters enhances oxygen reduction reactions. Nat. Chem 1, 397-402 (2009).

22. Chen, C. et al. Highly crystalline multimetallic nanoframes with threedimensional electrocatalytic surfaces. Science 343, 1339-1343 (2014).

23. Greeley, J. et al. Alloys of platinum and early transition metals as oxygen reduction electrocatalysts. Nat. Chem. 1, 552-556 (2009).

24. Strasser, P. et al. Lattice-strain control of the activity in dealloyed core-shell fuel cell catalysts. Nat. Chem. 2, 454-460 (2010).

25. Bashyam, R. \& Zelenay, P. A class of non-precious metal composite catalysts for fuel cells. Nature 443, 63-66 (2006).

26. Liang, Y. Y. et al. $\mathrm{Co}_{3} \mathrm{O}_{4}$ nanocrystals on graphene as a synergistic catalyst for oxygen reduction reaction. Nat. Mater. 10, 780-786 (2011).

27. Maiyalagan, T. et al. Spinel-type lithium cobalt oxide as a bifunctional electrocatalyst for the oxygen evolution and oxygen reduction reactions. Nat. Commun. 5, 3949 (2014).

28. Suntivich, J. et al. Design principles for oxygen reduction activity on perovskite oxide catalysts for fuel cells and metal air batteries. Nat. Chem. 3, 546-550 (2011).

29. Cheng, F. Y. et al. Rapid room-temperature synthesis of nanocrystalline spinels as oxygen reduction and evolution electrocatalysts. Nat. Chem. 3, 79-84 (2011).

30. Zhang, M., de Respinis, M. \& Frei, H. Time-resolved observations of water oxidation intermediates on a cobalt oxide nanoparticle catalyst. Nat. Chem. 6, 362-367 (2014).
31. Bordeneuve, H. et al. Structure and electrical properties of single-phase cobalt manganese oxide spinels $\mathrm{Mn}_{3-\mathrm{x}} \mathrm{Co}_{\mathrm{x}} \mathrm{O}_{4}$ sintered classically and by spark plasma sintering (SPS). J. Solid State Chem. 182, 396-401 (2009).

32. $\mathrm{Hu}, \mathrm{Y}$. Y. et al. Origin of additional capacities in metal oxide lithium-ion battery electrodes. Nat. Mater. 12, 1130-1136 (2013).

33. Jiao, F. \& Frei, H. Nanostructured manganese oxide clusters supported on mesoporous silica as efficient oxygen-evolving catalysts. Chem. Commun. 46, 2920-2922 (2010).

34. Rojas, R. M., Vila, E., Garcia, O. \& de Vidales, J. L. M. Thermal behaviour and reactivity of manganese cobaltites $\mathrm{Mn}_{\mathrm{x}} \mathrm{Co}_{3-\mathrm{x}} \mathrm{O}_{4}(0.0<\mathrm{x}<1.0)$ obtained at low temperature. J. Mater. Chem. 4, 1635-1639 (1994).

35. Li, Y. G., Tan, B. \& Wu, Y. Y. Freestanding mesoporous quasi-single-crystalline $\mathrm{Co}_{3} \mathrm{O}_{4}$ nanowire arrays. J. Am. Chem. Soc. 128, 14258-14259 (2006).

36. Moore, T. E., Ellis, M. \& Selwood, P. W. Solid oxides and hydroxides of manganese. J. Am. Chem. Soc. 72, 856-866 (1950).

37. Shoemaker, D. P., Li, J. \& Seshadri, R. Unraveling atomic positions in an oxide spinel with two Jahn - Teller ions: local structure investigation of $\mathrm{CuMn}_{2} \mathrm{O}_{4}$. J. Am. Chem. Soc. 131, 11450-11457 (2009).

38. Roche, I., Chaînet, E., Chatenet, M. \& Vondrák, J. Carbon-supported manganese oxide nanoparticles as electrocatalysts for the oxygen reduction reaction (ORR) in alkaline medium: physical characterizations and ORR mechanism. J. Phys. Chem. C 111, 1434-1443 (2007).

39. Oh, S. H. et al. Synthesis of a metallic mesoporous pyrochlore as a catalyst for lithium $-\mathrm{O}_{2}$ batteries. Nat. Chem. 4, 1004-1010 (2012).

40. Cheng, F. Y. et al. Enhancing electrocatalytic oxygen reduction on $\mathrm{MnO}_{2}$ with vacancies. Angew. Chem. Int. Ed. 52, 2474-2477 (2013).

41. El-Deab, M. S. \& Ohsaka, T. Manganese oxide nanoparticles electrodeposited on platinum are superior to platinum for oxygen reduction. Angew. Chem. Int Ed. 45, 5963-5966 (2006).

42. Izumi, F. \& Ikeda, T. A Rietveld-analysis program RIETAN-98 and its applications to zeolites. Mater. Sci. Forum 321-324, 198-203 (2000).

\section{Acknowledgements}

This work was supported by the National Programs of 973 (2011CB935900), NSFC (21231005 and 21322101) and 111 Project (B12015 and IRT13R30). We thank Professor Xiaosong Liu for fruitful discussion on the results of synchrotron X-ray absorption spectroscopy.

\section{Author contributions}

C.L., F.C. and J.C. conceived and designed this work. C.L. conducted the synthesis, C.L. X.H. and Y.H. carried out the characterization and the electrochemical measurements. X.H., F.C. and C.J. co-wrote the manuscript. All authors discussed the data and commented on the manuscript. J.C. directed the research.

\section{Additional information}

Supplementary Information accompanies this paper at http://www.nature.com/ naturecommunications

Competing financial interests: The authors declare no competing financial interests.

Reprints and permission information is available online at http://npg.nature.com/ reprintsandpermissions/

How to cite this article: Li, C. et al. Phase and composition controllable synthesis of cobalt manganese spinel nanoparticles towards efficient oxygen electrocatalysis. Nat. Commun. 6:7345 doi: 10.1038/ncomms8345 (2015).

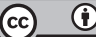

This work is licensed under a Creative Commons Attribution 4.0 International License. The images or other third party material in this article are included in the article's Creative Commons license, unless indicated otherwise in the credit line; if the material is not included under the Creative Commons license, users will need to obtain permission from the license holder to reproduce the material. To view a copy of this license, visit http://creativecommons.org/licenses/by/4.0/ 